\title{
Retention of a running response following appetitive acquisition, extinction, and discrimination
}

\author{
H. WAYNE LUDVIGSON \\ Texas Christian University, Fort Worth, Texas 76129 \\ PATRICIA G. MCCLEARY \\ Delta State University, Cleveland, Mississippi 38732 \\ and \\ CHERYL L. BOEDEKER \\ Texas Christian University, Forth Worth, Texas 76129
}

\begin{abstract}
In Experiment 1, hungry rats received 30 rewarded runway trials and then either extinction trials followed by retention tests or just retention tests. Different groups were tested after retention intervals of $1 \mathrm{~min}, 1,3$, or $24 \mathrm{~h}$, or 30 days. Retention of extinction training was a nonmonotonic, cubic function of time for the early portion of the response chain, with good retention at $1 \mathrm{~min}$ and $3 \mathrm{~h}$ and little retention at $1 \mathrm{~h}, 24 \mathrm{~h}$, or 30 days. In the latter portions of the response chain, retention of extinction decreased monotonically with time. Retention following reward-only training varied little in time, though slight losses occurred after 30 days. Experiments 2-3 differed from Experiment 1 in imposing nonchoice discrimination training (reward vs. nonreward) instead of extinction following 30 rewarded trials. After different time intervals $(.017, .75,1.25,3$, and $24 \mathrm{~h}$ in Experiment 1; and .017, 1, and $3 \mathrm{~h}$ in Experiment 2), retention tests revealed poorest discrimination at intermediate intervals in the initial portion of the response chain, i.e., a Kamin effect appeared. The deficit seemed the result of a loss of response suppression to the cue that signaled nonreward. In latter segments of the response chain, a Kamin effect tended not to appear. Implications for a number of observations and theoretical views are noted.
\end{abstract}

In 1957 Kamin reported that retention of avoidance learning was a U-shaped function, with poorest retention at intermediate $(1-6 \mathrm{~h})$ intervals following original training. This "Kamin effect" has generally been considered "peculiar" (e.g., Mackintosh, 1974, p. 474) and limited to aversively motivated behavior (Spear, 1978). However, recent conceptualizations have tried to assimilate it to more ubiquitous phenomena. Thus, Spear (1971) has argued that it may simply be one instance of a failure of retrieval and not really a "curious anomaly in animal memory" (Spear, 1978, p. 186). Furthermore, recent reports of multiphasic retention functions, both in aversive (Elson, Seybert, \& Ghiselli, 1977; Holloway \& Wansley, 1973) and appetitive (Hunsicker \& Mellgren, 1977; Wansley \& Holloway, 1975) tasks, as well as a report of the more typical

Experiment 1 is based on a dissertation by P. G. McCleary submitted to the Graduate School of Texas Christian University in partial fulfillment of the requirements for the degree of Doctor of Philosophy. The research was supported, in part, by a grant to the first author from the Texas Christian University Research Foundation. Reprints may be obtained from Dr. H. W. Ludvigson, Department of Psychology, Texas Christian University, Fort Worth, Texas 76129.
Kamin effect in appetitive discrimination reversal (Tribhowan, Rucker, \& McDiarmid, 1971), have raised the possibility that nonmonotonic retention functions, if not precisely Kamin effects, may be more prevalent than previously thought.

The present studies explored this possibility with respect to retention of extinction or frustrative nonreward of an appetitive running response. Given the literature on "spontaneous recovery," one might expect an appetitive response to gain strength following extinction, that is, exhibit some loss of extinction. Whether the effects of extinction return at longer intervals is not known, however, and certainly the implicit assumption of the sponanteous recovery literature is that they would not. Experiment 1 investigated retention of extinction in a nondiscriminative task. To provide a baseline for assessing retention of extinction, retention of reward training only was also assessed.

\section{EXPERIMENT 1}

\section{Method}

Subjects. The subjects were 120 naive male Holtzman rats, 90110 days old at the outset and individually housed under constant illumination. They were reduced to $80 \%$ of their preexperi- 
mental ad-lib weight during the week prior to the start of training and so maintained.

Apparatus. A runway, $7.5 \mathrm{~cm}$ wide, $9 \mathrm{~cm}$ high, painted flat white with Plexiglas top, was divided into a $30.5-\mathrm{cm}$ startbox, a $152.5-\mathrm{cm}$ run section, and a $30.5-\mathrm{cm}$ goalbox by guillotine doors. Photoelectric cells, $16.2 \mathrm{~cm}, 1.37 \mathrm{~m}$, and $1.68 \mathrm{~m}$ beyond the startdoor, yielded, in conjunction with a startbox microswitch, three measures of response speed, expressed in meters/second and termed start, run, and goal speeds. Illumination.came from a bank of $127-\mathrm{W}, 110 . \mathrm{V}$ lamps, $1.31 \mathrm{~m}$ above the runway floor and diffused by clouded Plexiglas.

Design. There were two preretention conditions, an acquisitiononly (termed "acquisition") condition and an acquisitionextinction (termed "extinction") condition, and five retention intervals. During acquisition, each animal received 30 rewarded trials. Five groups $(n=12)$, with different retention intervals ( $1 \mathrm{~min}, 1,3$, or $24 \mathrm{~h}$, or 30 days) between the last trial of acquisition and the first test for retention, were assigned to the acquisition condition. Similarly, five groups $(n=6)$, also differing in retention interval, were assigned to each of two extinction conditions, $E$ and EP. In Condition E, 30 rewarded trials were followed by 10 regular extinction trials. In Condition EP, 30 rewarded trials were followed by 10 regular extinction trials, plus 10 "placement" trials in which the animals were directly placed into the empty goalbox.

Procedure. Four days before training, the rats were individually handled for $2 \mathrm{~min}$ per day. Two days before training, the animals explored the runway freely for $2 \mathrm{~min}$ and were given $10.045 \mathrm{~g}$ Noyes pellets in their daily ration.

During reward training, the startdoor was opened after the rat had been in the startbox $3 \mathrm{sec}$. After the rat ate the $12.045 \mathrm{~g}$ Noyes pellets available in the goalbox (approximately $30 \mathrm{sec}$ ), it was returned to its home cage and another rat from the same group was given an acquisition trial. Trials alternated between a given couplet of rats until they had received their six daily ac- quisition trials. Two animals from each group of the acquisition condition were run thus at weekly intervals for 6 consecutive weeks. Animals from the extinction condition were run concurrently and similarly, except that the division of this condition into subtreatments E and EP required that two animals from each group of a subtreatment be run at biweekly intervals. Time of day of running a given rat was constant and, over the 6 weeks, approximately counterbalanced across groups.

Extinction groups received their extinction $24 \mathrm{~h}$ after the last acquisition trial. Trials were massed, and an animal was held $30 \mathrm{sec}$ in the goalbox containing the empty reward cup. Six retention test trials were given to each animal after its assigned retention interval. These were identical in procedure to the original acquisition. Air in the runway was exhausted continuously by a fan, and paper on the runway floor was changed following each trial to control for odor contamination (Ludvigson, 1969).

At the end of a training day, the subjects received daily rations. Time between training trials and feeding varied systematically among animals in any group, but equally across groups, from about $20 \mathrm{~min}$ to $9 \mathrm{~h}$. On retention test days, trials necessarily occurred later in the day for 1- and 3-h groups, but for only a few animals did tests occur after the normal feeding time, and then by not more than $100 \mathrm{~min}$. The 30 -day groups were given free access to food from the end of their original training until 1 week prior to the retention test; then $80 \%$ deprivation rations were reinstituted.

\section{Results}

Response speeds on the six test trials are presented in Figure 1.

Reward Training. Analyses of variance of the last six reward training trials were performed on each response measure. No significant differences were
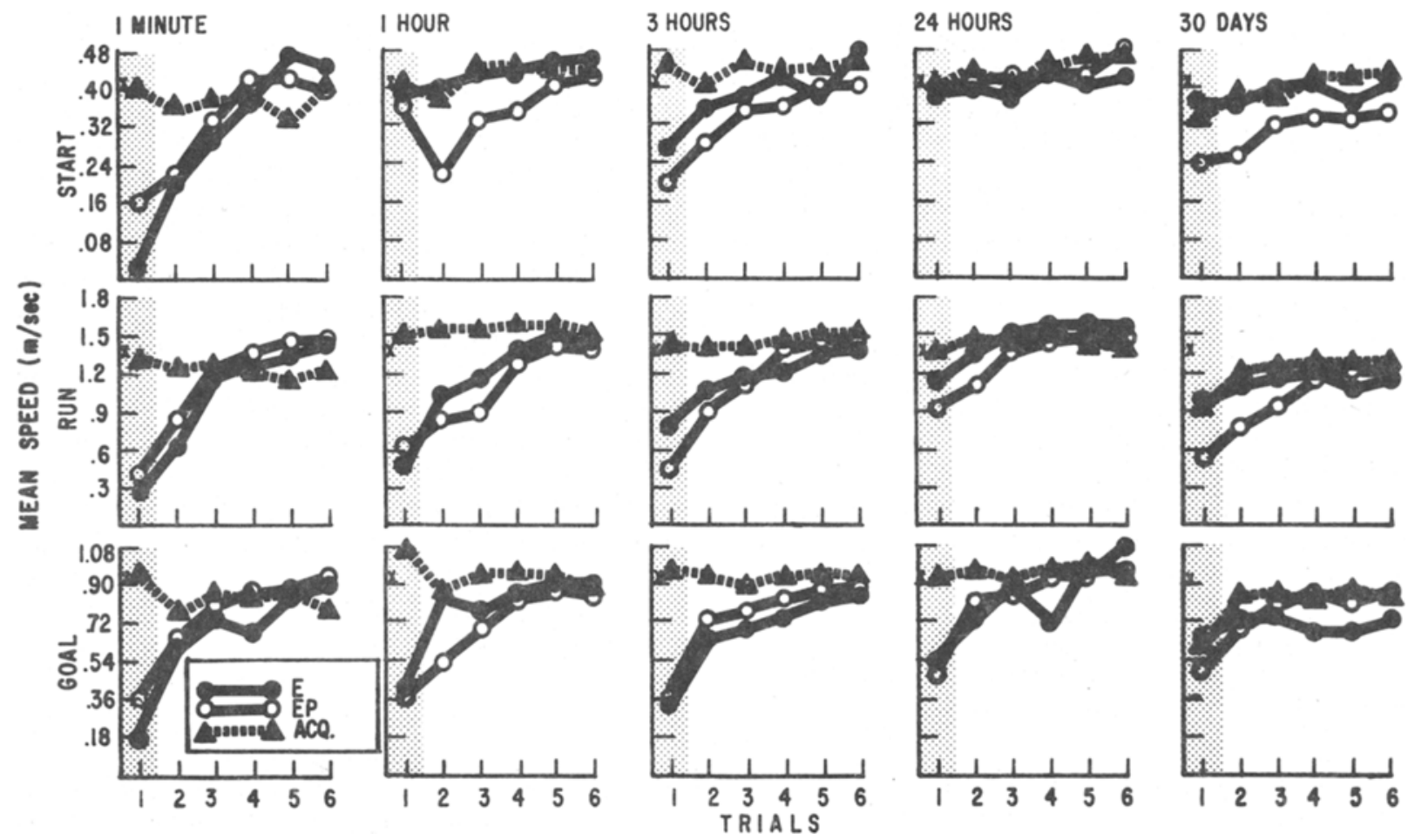

Figure 1. Experiment 1: Mean response speeds for conditions as a function of test trials. Data are preserted for start, run, and goal measures at each retention interval. The first test trial is presented in the shaded portion of the graphs. The Xs represent terminal performance during reward training. 
revealed. The mean levels of performance during these trials are represented by Xs in Figure 1.

Retention of acquisition training: First test trial. To examine the retention of acquisition training for the occurrence of retention "lapses," that is, decrements measured before reexposure to the reinforcement conditions (Spear, 1971), analyses of variance were performed on the acquisition condition's firsttest-trial data. For the start measure, retention interval was not significant, but for the run and goal measures, it was [run: $F(4,55)=7.50, p<.01$; goal: $F(4,55)=12.37, p<.01$ ]. Subsequent tests with the Newman-Keuls procedure revealed that speed at 30 days was significantly lower $(p<.01)$ than at the other intervals in both the run and goal measures.

Retention of acquisition training: Test Trials 2-6. To assess any retention "loss," that is, a decrement in the rate of relearning after the reinstitution of reinforcement conditions (Spear, 1971), among acquisition groups, analyses were performed across Test Trials 2-6. For the start measure, no variation with retention interval was revealed; however, a significant trials effect was noted $[F(4,220)=3.66, p<$ .01] with a subsequent Newman-Keuls test indicating significant depression $(p<.05)$ in speed on Test Trial 2. For the run measure, retention interval was significant $[F(4,55)=4.34, p<.01]$, with a Newman-Keuls test showing a loss in retention at 30 days $(\mathrm{p}<.01)$. In the goal measure, retention interval was significant $[\mathrm{F}(4,55)=2.78, \mathrm{p}<.05]$, with the Newman-Keuls test indicating that speed at $24 \mathrm{~h}$ was faster than at $1 \mathrm{~min}(\mathrm{p}<.05)$.

Retention of extinction training: First test trial. Since test trials were reinforced, retention of extinction was confounded with reacquisition on all but the first trial. Thus, similar to the distinction between a lapse and a loss, the first test trial represents the retained effects of extinction prior to reexposure to reward training, while the remaining five test trials reflect the effect of extinction on relearning. Consequently, performance on the first test trial was subjected to separate analysis and considered the "purest" measure of the retention of extinction. Preliminary comparisons of Conditions E and EP revealed no significant differences. Therefore, they were combined in subsequent analyses.

To obtain a picture of retention-of-extinction training uncomplicated by retention-of-acquisition effects, first-test-trial difference scores were calculated for each extinction group by subtracting its mean speed from the mean speed of the acquisition condition at the corresponding retention interval. Such difference scores are presented in Figure 2 for the start measure, the only measure to display clearly a nonmonotonic function. As above, however, analyses were performed on the original data represented in Figure 1.

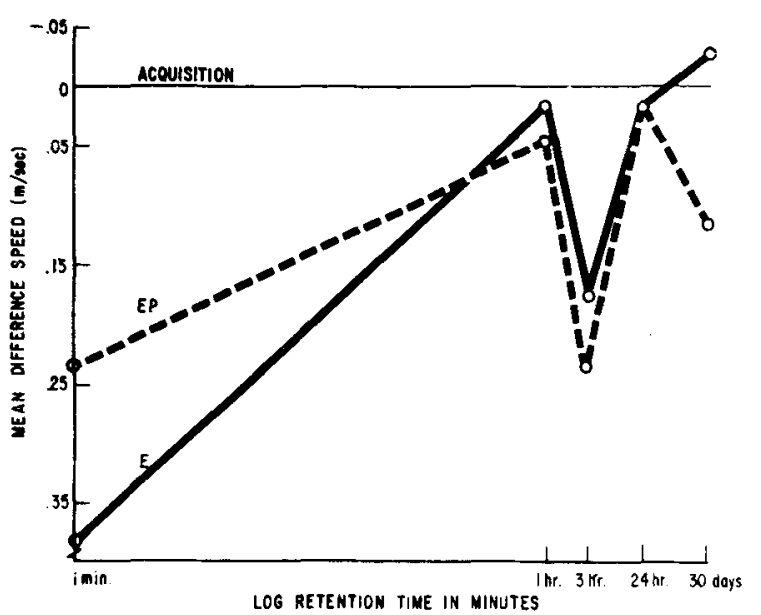

Figure 2. Experiment 1: Mean start speed for conditions $E$ and EP on the first test trial as a function of retention interval. Data are expressed as differences between extinction conditions and corresponding acquisition conditions.

Analysis of start speeds comparing the combined extinction conditions with the acquisition condition on the first test trial resulted in significant effects of conditions $[\mathrm{F}(1,110)=44.67, \mathrm{p}<.005]$, retention intervals $[\mathrm{F}(4,110)=7.56, \mathrm{p}<.005]$, and Conditions by Retention Intervals $[F(4,110)=$ $11.07, \mathrm{p}<.005]$. Tests of simple effects yielded significant differences between the combined extinction conditions and the acquisition conditions at $1 \mathrm{~min}[\mathrm{~F}(1,110)=57.44, \mathrm{p}<.005]$ and at $3 \mathrm{~h}$ $[F(1,110)=24.79, p<.005]$, but no differences at the remaining intervals.

Similar analysis of run speeds indicated effects of conditions $[F(1,110)=122.89, p<.005]$, retention interval $[F(4,110)=5.62, p<.005]$, and their interaction $[F(4,110)=8.30, p<.005]$. Analysis of simple effects found significant differences between conditions at all retention intervals, except 30 days [1 min: $\mathrm{F}(1,110)=52.78, \mathrm{p}<.005 ; 1 \mathrm{~h}: \mathrm{F}(1,110)=$ $51.37, \mathrm{p}<.005 ; 3 \mathrm{~h}: \mathrm{F}(1,110)=43.99, \mathrm{p}<.005$; and $24 \mathrm{~h}: \mathrm{F}(1,110)=5.46, \mathrm{p}<.05$ ].

For goal speeds, the condition $[\mathrm{F}(1,110)=175.12$, $\mathrm{p}<.005]$ and the Condition by Retention Interval effects $[F(4,110)=10.56, p<.005]$ were significant Subsequent tests revealed significant differences between extinction and acquisition conditions at each retention interval except 30 days $[\mathrm{Fs}(1,110)=61.11$, $65.95,56.31$, and $27.84, \mathrm{p}<.005$, for $1 \mathrm{~min}, 1$, 3 , and $24 \mathrm{~h}$, respectively].

Retention of extinction training: Test Trials 2-6. The trend for the extinction conditions across Trials 2-6 was initial suppression followed by recovery (see Figure 1), with two exceptions. In the 24-h start measure and the 30-day goal measure, analysis revealed nonsignificant effects.

\section{Discussion}

This study provides evidence for a Kamin-type 
retention loss at intermediate intervals after appetitive nonreinforcement, though restricted to the early portion of the response chain (the start measure) and limited largely to the first test trial. Instead of the often-found U-shaped function, however, a cubic function was observed, in which retention of extinction first declined, then increased, and then again declined. Thus, an ultimate forgetting, or at least disappearance, of the effects of extinction occurred.

\section{EXPERIMENT 2}

Though provocative, the evidence from Experiment 1 was rather tenuous with regard to retention of extinction. That is, had it not been for better retention at $3 \mathrm{~h}$ than at surrounding intervals, the data simply would have indicated decreasing retention as a function of retention interval, that is, simple spontaneous recovery of running. Furthermore, the effect was confined to the initial portion of the response chain.

Given this, the experiment was replicated in our laboratory (Ludvigson \& McNeese, Note 1). In a study almost identical to Experiment 1, the nonmonotonic effect was not found. Instead, retention of extinction simply decreased with time.

The problem was considered from the standpoint that both results just might be genuine. We noted that if the retention deficit were peculiar to the initial segments of the response chain (or more accurately, to the processes occurring at the outset of a trial), as Experiment 1 suggested, the effect might be difficult to obtain with a simple nondiscriminative task, because it is not clear when a trial "functionally" begins. That is, the processes that initiate the response, including, presumably, retrieval of critical information from memory, are not under precise experimental control. Thus, it is not clear where to measure the initial portions of the chain of events comprising a trial. In this nondiscriminative task, a trial can functionally begin before the startdoor is opened and even before the animal is placed into the apparatus, judging from other data (e.g., Harris, Collerain, Wolf, \& Ludvigson, 1970; Ludvigson \& Gay, 1967). Since a response is not normally measured prior to placing the animal into the apparatus, it seems possible that the retention deficit could occur and disappear before the response is measured.

It seemed to us that a discrimination task might permit better control of trial initiation and retrieval. That is, if extinction were associated with a specific discriminative stimulus $(\mathrm{S}-$ ) and reward associated with another stimulus $(\mathrm{S}+)$, and the subject were not to know which stimulus was going to be presented until measurement of the response began, retention deficits associated with the initial portion of the response chain immediately after the presentation of the $\mathrm{S}$ - stimulus might be found. The present experiment tested this hypothesis.

\section{Method}

The method differed from Experiment 1 as described below. Fifty female Holtzman rats, 90 to 100 days old, were randomly assigned to five groups. An additional photocell was located $.76 \mathrm{~m}$ beyond the startdoor to permit the run speed measure to be subdivided into two measures, called Run 1 and Run 2. A time-to-orient measure (time between the placing of a subject into the startbox and the opening of the startgate) was also taken as a control for extraneous cues before the opening of the staridoor.

The overhead illumination provided the $S+$ cue. A strip of coarse sandpaper extending approximately $17.6 \mathrm{~cm}$ into the alley from the startdoor, in conjunction with extinguishing the overhead lamps at the moment the startgate was raised, provided the $\mathrm{S}$ cue for nonreward.

The experiment comprised three phases: (1) acquisition, or 30 rewarded trials (6/day) to $S+$, (2) discrimination, 10 nonrewarded $(-)$ trials to $S-$ interspersed among 10 rewarded $(+)$ trials to $S+$ in the order, $+--+++-\cdots++--++++-+-$, and (3) a retention test of six discrimination trials following a variable retention interval. Five groups of subjects differed only in retention interval: $.017(1 \mathrm{~min}), .75,1.25,3.0$, and $24.0 \mathrm{~h}$ between the end of discrimination training and the first retention test. Each group was divided into two subgroups, one of which received +-+-+- as its sequence of $S+$ and $S-$ trials during the retention test, and the other of which received -+-+-+ .

A trial began by requiring a subject to orient toward the startgate for $3 \mathrm{sec}$ before the gate was opened. Reinforcement was six pellets. Fewer squads were run per day; thus, time between trials and feeding varied within groups from about $20 \mathrm{~min}$ to $4.3 \mathrm{~h}$.

Twenty-four hours following acquisition, each subject was run alone for 20 discrimination trials, with an intertrial interval of about $1 \mathrm{~min}$. Rentention tests were identical to discrimination trials. Following each trial, paper located on the floor of the runway was changed and the air exhausted for $1 \mathrm{~min}$. A clean sandpaper strip was provided before each nonrewarded trial.

\section{Results}

Preliminary analyses found that (1) whether an $S+$ or an $\mathrm{S}$ - came first in the test series made no difference, and (2) orienting speeds indicated that subjects did not receive extraneous discriminative cues prior to the opening of the startdoor. Therefore, neither of these matters will be discussed further.

Discrimination training: Last four trials. Analysis of the final four discrimination trials revealed no significant differences among groups prior to retention. Differences between $\mathrm{S}+$ and $\mathrm{S}-$ speeds, indicative of discrimination, were found in all measures $(p<.01)$.

Retention of discrimination training: First test trials. Mean speeds for the first two test trials, one $S+$ and one $S-$, are presented in Figure 3. In the start measure, a significant discrimination between $\mathrm{S}+$ and $\mathrm{S}$ - trials appeared $[F(1,45)=63.45, p<.001]$, as well as significant variation in discrimination as a function of retention interval $[F(4,45)=4.57, p<.01]$. The interaction arose from a quadratic trend $[F(1,45)=$ $5.26, \mathrm{p}<.05$ ] produced by diminution of discrimination at the .75 - and $1.25-\mathrm{h}$ time intervals. Separate $\mathrm{t}$ tests comparing the means of the $\mathrm{S}+$ and $\mathrm{S}-$ trials at these two time intervals yielded nonsignificant differences.

In the Run 1 measure, only a significant discrimination appeared $[\mathrm{F}(1,45)=42.45, \mathrm{p}<.001]$. The Run 2 measure also yielded a significant discrimination $[\mathrm{F}(1,45)=63.25, \mathrm{p}<.001]$, as well as an interaction 


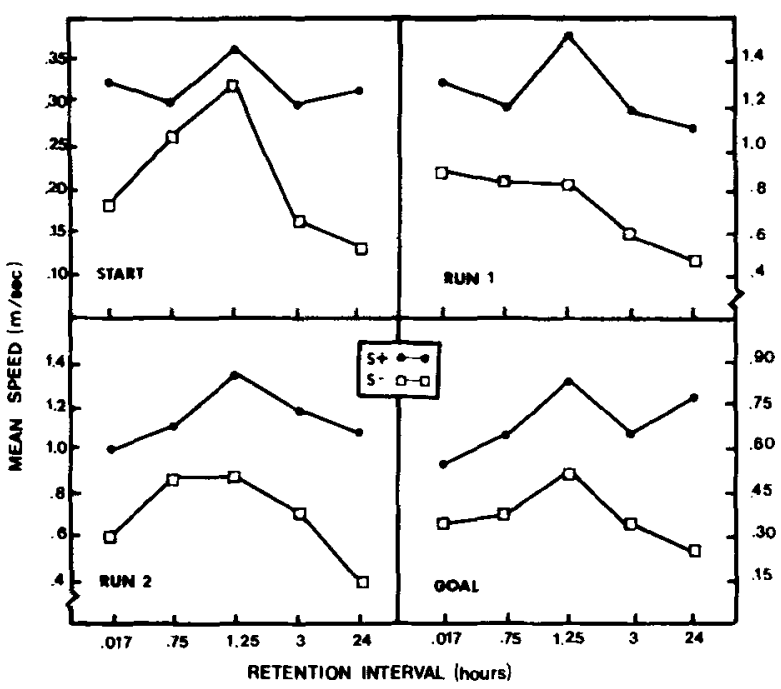

Figure 3. Experiment 2: Mean speed for the several response measures on the first lest trials of the retention test.

with retention interval $[F(4,45)=2.95, p<.05]$. Trend analysis on the latter found significant linear and cubic components $[\mathrm{Fs}(1,45)=5.8$ and 6.6 , respectively, $\mathrm{p}<.05$ ], supporting the graphic impression that the discrimination increased with retention interval, except at the .75 interval, where it decreased. However, a t test at this interval indicated that the discrimination, though diminshed, was present $[\mathrm{t}(9)$ $=2.08, \mathrm{p}<.05]$.

Goal speeds also yielded significant discrimination $[\mathrm{F}(1,45)=96.80, \mathrm{p}<.001]$ and Discrimination by Retention Interval $[F(4,45)=2.94, p<.05]$ effects. The interaction arose from a linear trend $[F(1,45)$ $=12.73, \mathrm{p}<.001]$, with discrimination regularly increasing with an increase in retention interval.

Retention of discrimination training: Trials 3-6. Separate analyses revealed significant discrimination between $\mathrm{S}+$ and $\mathrm{S}$ - trials in all runway sections, both on Trials $3-4$ and on Trials 5-6 (p $<.01)$. However, discrimination was not significantly affected by retention time.

\section{Discussion}

The data of Experiment 2 bear substantial resemblance to those of Experiment 1. A Kamin effect was observed, it evidenced itself in a loss of nonreinforcement-produced response suppression, and it appeared strongest in the initial segment of the response chain. Given these results, the hypothesis enunciated above regarding the difficulty of demonstrating the Kamin effect in the simple nondiscriminative runway task receives some support.

\section{EXPERIMENT 3}

A second study was designed to increase the generality and assess the replicability of these results. Subjects were tested in a slightly different apparatus, and male rather than female rats were used. Only three retention intervals, those appearing to be most crucial in demonstrating the Kamin effect, were tested. Furthermore, three, rather than four, response measures were recorded.

\section{Method}

The method was the same as before except as noted. Data came from three randomly formed groups (14/group) of male Holtzman rats, 90 to 110 days old when placed on deprivation. The runway was $10 \mathrm{~cm}$ high and $6 \mathrm{~cm}$ wide, with a $28-\mathrm{cm}$ startbox, a $120-\mathrm{cm}$ run section, and a $39-\mathrm{cm}$ goalbox. Photoelectric cells were placed $.152,1.35$, and $1.65 \mathrm{~m}$ beyond the startdoor. The sides of the run and goal sections could be dimly illuminated by 48 equally spaced, $2.5-\mathrm{W}$, miniature lamps, to which $10 \mathrm{~V}$ of electricity were applied. This light was diffused by clouded Plexiglas walls, and its presence or absence was unobservable to the subject until the startgate was raised. These lamps provided the $\mathrm{S}+$ cue. The absence of the light cue in conjunction with a strip of coarse sandpaper extending into the alley, as in Experiment 2 , provided the $S$ - cue. The startbox was continuously illuminated. The three retention intervals were $.017(1 \mathrm{~min}), 1$, and $3 \mathrm{~h}$. Only four test trials were given, in the order of either +-+- or -+-+

\section{Results}

There were no significant differences between subgroups receiving the different test trial sequences. Thus, this factor will not be discussed further.

Discrimination training: Last four trials. Significant differences between $\mathrm{S}+$ and $\mathrm{S}-$ speeds on the last four discrimination trials were found in the start and run sections ( $\mathrm{p}<.025$ and .01 , respectively), but not in the goal measure $(F<1)$.

Although the groups were formed randomly, they differed systematically in overall performance levels on the last four discrimination trials prior to receiving differential treatment. There were significant group differences in running speeds $[\mathrm{F}(2,39)=5.0, \mathrm{p}<$ $.025]$ and differences which approached significance in the start speeds $[\mathrm{F}(2,39)=2.5, \mathrm{p}<.10]$, though none in the goal speeds. To compensate for these chance differences in mean performance level, it was assumed that the differences exhibited at the end of discrimination were characteristic of such overall differences during the retention tests. Therefore, the retention data for a group of subjects were corrected by an amount reflecting the deviation of that group. from the mean for all subjects during the last four discrimination trials. Although the correction altered the overall levels of the groups, it left unaffected the crucial differences between $\mathrm{S}+$ and $\mathrm{S}-$ speeds indicative of the magnitude of the discrimination in retention. Only corrected scores are discussed below, but uncorrected scores may be calculated from the correction factors in Table 1.

Retention of discrimination training: First test trial. Data from the initial two test trials, one $S+$ and one $\mathrm{S}-$ are presented in Figure 4. In the start measure, discrimination between $\mathrm{S}+$ and $\mathrm{S}-$ was significant $[F(1,39)=28.63, p<.001]$, as was the interaction with retention interval $[\mathrm{F}(2,39)=3.23, \mathrm{p}<.05]$. The interaction arose from a quadratic component 
Table 1

Experiment 3 Correction Factors for Retention Data Based on Group Differences at the End of Discrimination

\begin{tabular}{crrr}
\hline & \multicolumn{3}{c}{ Speed Measures } \\
\cline { 2 - 4 } Group & Start & Run & Goal \\
\hline .017 & -.02 & -.09 & -.03 \\
1.00 & .02 & .01 & -.10 \\
3.00 & .00 & .08 & .04 \\
\hline
\end{tabular}

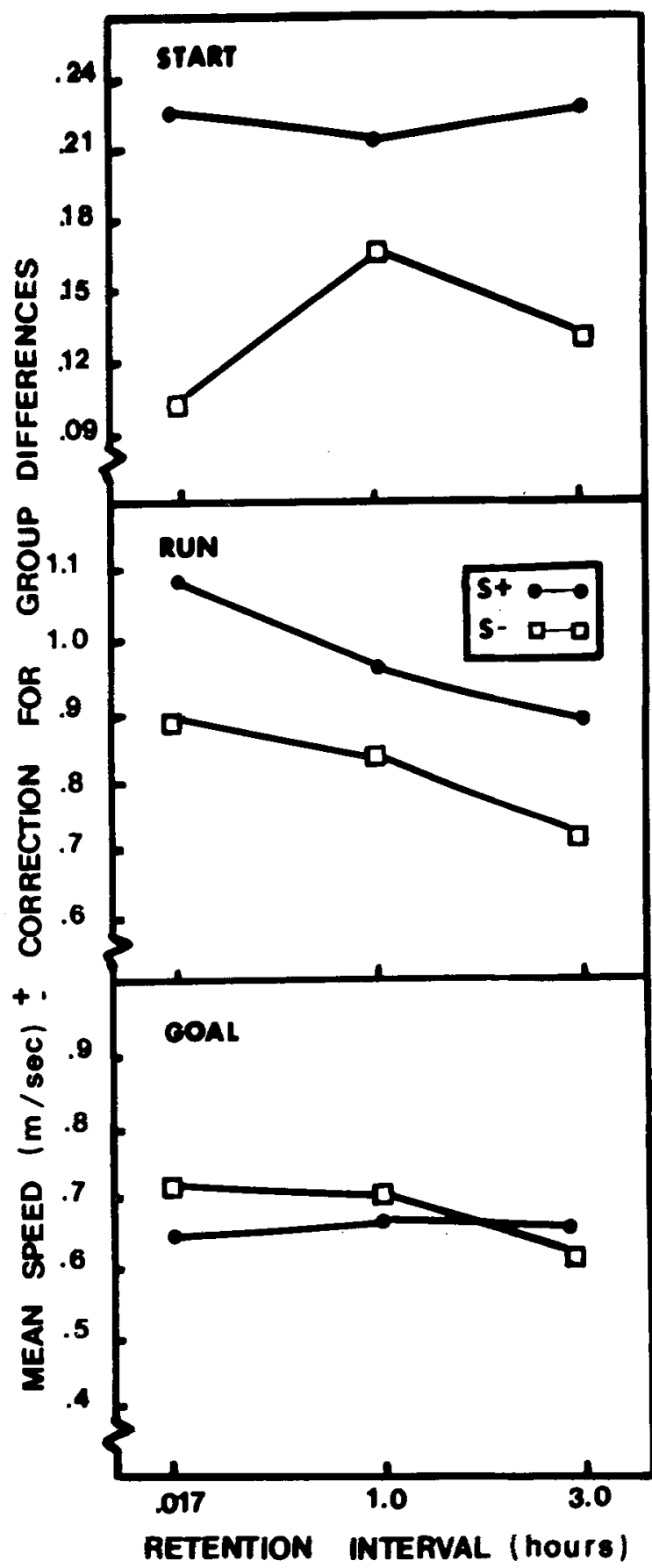

Figure 4. Experiment 3: Mean speed, corrected for group differences, for the several response measures, on the first test trials of the retention test.
$[F(1,39)=4.13, p<.05]$, with a decrease in discrimination magnitude at $1 \mathrm{~h}$. A test of the $\mathrm{S}+$ vs. $\mathrm{S}-$ difference at $1 \mathrm{~h}$ found it not to be significant. In the run measure, only a significant discrimination appeared $[\mathrm{F}(1,39)=4.89, \mathrm{p}<.03]$. Goal scores revealed no significant effects.

Retention of discrimination training: Trials 3-4. Only a significant discrimination appeared in the start measure $[F(1,39)=6.7, p<.01]$.

\section{Discussion}

The results of Experiment 2 were generally confirmed in Experiment 3. A retention deficit like the Kamin effect was found in the start measure on the initial two trials, but not in the run measure. Furthermore, the deficit seemed to be the result of a loss of suppression to $\mathrm{S}-$. However, discrimination was not observed in the goal measure, and, consequently, retention of discrimination could not be evaluated there. Such an absence or diminution of discrimination in latter segments of the response chain is not particularly unusual (e.g., Harris et al., 1970; Ludvigson \& R. A. Gay, 1967; Ludvigson \& S. E. Gay, 1966).

\section{GENERAL DISCUSSION}

The present studies were principally concerned with exploring the hypothesis that retention of the effects of extinction or frustrative nonreward follows a nonmonotonic function. All three studies found nonmonotonic functions in contrast to the usual implications of the concept of spontaneous recovery. Viewed in this way, perhaps spontaneous recovery results from measuring response strength at a low point in a nonmonotonic process governing retention of extinction. Obviously, whether such a subsumption of spontaneous recovery is justified will require further research.

Regardless of whether spontaneous recovery is a special case of nonmonotonic retention, it is not certain that the nonmonotonic functions reported here should be considered Kamin effects. Certainly, the restriction of nonmonotonicity to the first retention test is atypical for Kamin effects, since they often fail to appear there, but typical of instances said to exhibit proactive interference, including spontaneous recovery (Spear, 1971). Nevertheless, a tentative affinity between the phenomena seems reasonable, given our present knowledge.

\section{Implication of Nonmonotonicity Restricted to Initial Portion of Response Chain}

The major contribution of the present studies may reside in showing nonmonotonic retention deficits to be rather specific to the initial portion of the response chain. Prior studies may not have revealed this simply because they recorded only a single measure of a large portion of the response chain. It would appear 
that those processes occurring at the functional beginning of a trial are most susceptible to the retention loss, leaving subsequent processes relatively unaffected. ${ }^{1}$ What is suggested is that the temporally dependent retention deficits arise from difficulty in retrieving information from long-term memory, a difficulty that may be rapidly overcome soon after onset of retrieval-stimulating cues.

\section{Kamin Effect in Lateny But Not Choice}

This analysis would seem to apply to the observation of Barrett, Leith, and Ray (1971) and Steranka and Barrett (1973) of a Kamin effect in response latency, but not choice, in a Y-maze discriminatedavoidance task. Initiation of avoidance, reflected in latency, may reasonably be said to have preceded the choice response. Thus, one is not justified in rejecting a memory-deficit interpretation of the Kamin effect, as did these authors, upon the observation that it can occur in one measure but not in another, later measure.

The findings of Bryan and Spear (1976) are more difficult to explain with the present analysis, since they obtained a Kamin effect in a choice response using a T-maze, discriminated escape, task (escape latencies were not recorded). Why was the retrieval deficit not overcome by the time choice occurred? Probably many factors control the rapidity or probability of the recovery. For example, if motivating conditions encourage a speedy response before retrieval processes can offset a deficit, or if motivating conditions themselves interfere with information processing, then the deficit may not be overcome. The use of an escape task with its electric shock invariably accompanying trial outset could have provided such motivating conditions.

\section{One-Way vs. Two-Way Avoidance}

The present analysis might also apply to the observation that the Kamin effect is more likely to be found in two-way than in one-way active avoidance (Anisman, 1973). The one-way task is like the simple runway task of our first studies in that all cues preceding the response equally signal the current goal event. In contrast, the two-way task is somewhat like the discriminative task used in the present studies: cues preceding the stimulus do not very reliably signal a particular goal event. In the two-way task, most such "intertrial" cues are present during periods of safety following shock offset, as well as during shock onset; only temporal cues could be discriminative. It is consistent, therefore, that the two-way task should more reliably yield Kamin effects. Presumably, control over the retrieval-stimulating cues is superior.

\section{Internal States and the Context of Cues}

The present results seem consistent with an extension of a hypothesis (Spear, 1971) that retrieval is dependent on the similarity of the context of cues present during retention tests and training. During training, internal "state" stimuli (e.g., from neurochemical states) and "nonstate" stimuli (e.g., runway cues, proprioceptive cues) are presumed to become associated with excitatory or inhibitory tendencies generated by goal experiences. Stress, or, as applied here, frustrative nonreward, produces a characteristic internal state (call it state F), which disappears with time or is replaced spontaneously by another state. This latter state, call it state AF, since it comes after $\mathrm{F}$ and may be antagonistic to F (cf. Solomon \& Corbitt, 1974), to the extent it differs from state $F$, would contribute to a memory deficit for events associated with state $F$. Thus, the loss of extinctive or discriminative inhibition in the start speed measures of the present studies around the 1-h retention interval would be seen as the result of the replacement of state $\mathrm{F}$ by $\mathrm{AF}^{2}{ }^{2}$

Going beyond Spear's hypothesis, it seems reasonable that as the animal traverses the alley there is an increase in the number or relative salience of nonstate cues sufficient to offset the temporary deficit resulting from the change in state cues. Or nonstate cues might reinstate, via association, the state (in this case state F) present during training. In either case, inhibition aroused by state $F$ would be reactivated, thus explaining the absence of the Kamin effect later in the chain of events comprising a trial (i.e., in run or goal speeds). Similarly, the disappearance of the Kamin effect on later retention trials would be explained by postulating the reestablishment of the internal state characteristic of the training phase, since retention tests utilized training conditions.

Although assumptions of this kind seem applicable to the present data, a precise explanation of the following require further elaborations and assumptions:

(1) The absence of a Kamin loss in the excitatory tendency-An additional assumption seems necessary, such as (1) state AF is similar to the state present during initial training involving only reinforcement, (2) inhibition generalizes more steeply than excitation, or (3) excitation was more associated with nonstate cues than was inhibition, rendering it relatively immune to disruption from internal state changes.

(2) The return of inhibition in start speeds at $3 \mathrm{~h}$-Perhaps state AF dissipated, permitting state F (or a conditioned form of state $F$ ) to be reinstated at the outset of the $3 \mathrm{~h}$ test trial.

(3) The increasingly greater amount of extinctive suppression evidenced in start through goal speeds at $24 \mathrm{~h}$ in Experiment 1 -If, after $24 \mathrm{~h}$, whatever processes responsible for proactive interference come into play, then excitation should gain relative to inhibition and produce fast start speeds. Further assuming that the increase in relevant retrieval cues as the animal traverses the runway produces a more accurate representation of recent training experience, inhibition should be increasingly reinstated, yielding 
the observed speed gradient. That a similar gradient did not appear in Experiments 2 and 3 might simply be attributable to the use of a discrimination task, which would encourage more exclusive association of inhibition with $\mathrm{S}$ - .

(4) The drop in performance by all animals on the first test trial after 30 days in Experiment 1-A general long-term retention lapse, to which all tendencies are susceptible, including proactively interfering tendencies, would describe, though not explain this.

\section{Associative Processes vs. Response Suppression}

Although it is reasonable to suppose that underlying the Kamin effect are various changes in physiological state (Anisman, 1975; Brush, 1971), the further assumptions that such changes produce not a retention loss but a general lowering of activity level (Barrett et al., 1971; Steranka \& Barrett, 1973) or ability to initiate responding (Anisman, 1975) are quire inapplicable to the present studies for two reasons: (1) retention loss was evidenced by quickened response initiation, and (2) response initiation to $\mathrm{S}+$ in Experiments 2-3 was not lowered. The former also rules out an appeal to emotion-engendered immobility (Denny \& Ditchman, 1962). More generally, the present data join others' (cf. Spear, 1971, 1978) in contributing to the unattractiveness of any hypothesis that appeals exclusively to direct depression of performance as the underlying mechanism.

\section{REFERENCE NOTE}

1. Ludvigson, H. W., \& McNeese, R. R. A monotonic retention function after extinction of an appetitively motivated response. Unpublished research report.

\section{REFERENCES}

Anisman, H. Cholinergic mechanisms and alterations in behavioral suppression as factors producing time-dependent changes in avoidance performance. Journal of Comparative and Physiological Psychology, 1973, 83, 465-477.

Anisman, H. Time dependent variables in aversively motivated behaviors: Nonassociative effects of cholinergic and catecholaminergic activity. Psychological Review, 1975, 82, 359-385.

BarketT, R. J. Leith, N. J., \& RAY, O. J. Kamin effect in rats: Index of memory or shock-induced inhibition? Journal of Comparative and Physiological Psychology, 1971, 77, 234-239.

Brush, F. R. Retention of aversively motivated behavior. In F. R. Brush (Ed.), Aversive conditioning and learning. New York: Academic Press, 1971.

Bryan, B. G., \& Spear, N. E. Forgetting of a discrimination after intervals of intermediate length: The Kamin effect with choice behavior. Journal of Experimental Psychology: Animal Behavior Processes, 1976, 2, 221-234.

Denny, M. R., \& Ditchman, R. E. The locus of the maximal "Kamin effect" in rats. Journal of Comparative and Physiological Psychology, 1962, 55, 1069-1070.

Elson, I. J., Seybert, J. A., \& Ghiselli, W. B. Retention of aversively motivated behavior: Effects of time of training and associative versus nonassociative processes. Behavioral Biology, 1977, 20, 337-353.

Harris, D. R., Collerain, I., Wolf, J. C., \& Ludvigson, H. W. Negative $S-$ contrast with minimally contingent large reward as a function of trial initiation procedure. Psychonomic Science, 1970, 19, 189-190.

Holloway, F. A., \& Wansley, R. Multiphasic retention deficits at periodic intervals after passive-avoidance learning. Science, 1973, 180, 208-210.

Hunsicker, J. P., \& Mellgren, R. L. Multiple deficits in the retention of an appetitively motivated behavior across a $24-\mathrm{h}$ period in rats. Animal Learning \& Behavior, 1977, 5, 14-16.

KAMIN, L. J. Retention of an incompletely learned avoidance response. Journal of Comparative and Physiological Psychology, 1957, 50, 457-460.

Ludvigson, H. W. Runway behavior of the rat as a function of intersubject reward contingencies and constancy of daily reward schedule. Psychonomic Science, 1969, 15, 41-43.

Ludvigson, H. W., \& G $\mathrm{AY}, \mathrm{R}$. A. An investigation of conditions determining contrast effects in differential reward conditioning. Journal of Experimental Psychology, 1967, 75, 37-42.

Ludvigson, H. W., \& GAY, S. E. Differential reward magnitude conditioning: $S-$ contrast as a function of the magnitude of S+ . Psychonomic Science, 1966, 5, 289-290.

Mackintosh, N. J. The psychology of animal learning. New York: Academic Press, 1974.

Solomon, R. L., \& CorbitT, J. D. An opponent-process theory of motivation: I. Temporal dynamics of affect. Psychological Review, 1974, 81, 119-145.

Spear, N. R. Forgetting as retrieval failure. In W. Honig \& P. H. R. James (Eds.), Animal memory. New York: Academic Press, 1971.

Spear, N. E. The processing of memories. Hillsdale, N.J: Erlbaum, 1978.

Steranka, L. W., \& Barrett, R. J. Kamin effect in rats: Differential retention or differential acquisition of an active avoidance response? Journal of Comparative and Physiological Psychology, 1973, 85, 324-330.

Tribhowan, T., Rucker, W. B., McDiarmid, C. G. Demonstration of a Kamin-like effect after appetitive training. Psychonomic Science, 1971, 23, 41-43.

Wansley, R. A., \& Holloway, F. A. Multiple retention deficits following one-trial appetitive training. Behavioral Biology, $1975,14,135-149$.

\section{NOTES}

1. This could account for the failure of Ludvigson and McNeese (Note 1) to replicate Experiment 1. In the latter, a subject was confined to the startbox for just $3 \mathrm{sec}$ before given access to the runway. In Ludvigson and McNeese, a subject had to orient to the door for $3 \mathrm{sec}$ before it was opened. In Experiment 1, then, a response measure might have been recorded earlier in the sequence of trial processes. Although Experiments 2 and 3 used a procedure like that of Ludvigson and McNeese, that factor should not have been critical for them; use of a discrimination task should have prevented the subject from anticipating the trial outcome until after the startdoor had been raised exposing the discriminative cue. Assuming critical memory processes do not begin until cue exposure, the discriminative task avoids the problem inherent in the nondiscriminative task of controlling the initiation of these memory processes.

2. It may be noted that while, in Experiment 1, stimuli from state $F$ would have been discriminative cues associated with extinctive inhibition only, in Experiments 2-3, they would have been associated with both excitation and inhibition during discrimination training. Thus, in the latter case, stimuli from state $F$ would have functioned as conditional cues, signaling the opportunity for a discrimination on the basis of the discriminative cues, $\mathrm{S}+$ and $\mathrm{S}-$.

(Received for publication November 27, 1978; revision accepted September 4, 1979.) 